\title{
Effectively Adapting and Implementing In-Person Teacher Professional Development to a Virtual Format
}

\author{
Katie Busch Chandran ${ }^{1}$, Kathy C. Haynie ${ }^{3}$, Rachael Tawbush ${ }^{4}$, and J. Michael Wyss $\mathbf{s}^{1,2}$ \\ ${ }^{1}$ Center for Community Outreach Development (CORD) and ${ }^{2}$ Departments of Cell, Developmental and Integrative Biology and Medicine, The University of Alabama at \\ Birmingham, Birmingham, AL; ${ }^{3}$ Haynie Research and Evaluation, Skillman, NJ; and ${ }^{4}$ Georgia Southwestern State University, Americus, GA \\ Keywords: STEM, teacher professional development, virtual learning, online learning, teacher workshop, science education \\ Publication Date: August 30, 2021 \\ DOI: https://doi.org/10.15695/jstem/v4i3.12
}

\begin{abstract}
A year of COVID-19 quarantine required educators to switch from in-person to virtual learning platforms, causing a dramatic reimagining of their daily praxis. Their experiences are likely to influence new norms for K-12 education. While virtual learning can be effective, student engagement, student retention, and student attention can be challenging. This paper discusses how we adapted a materials-heavy, hands-on, annual summer teacher professional development (PD) program from an in-person to a virtual platform in the initial months of the pandemic. We successfully maintained effective and hands-on components, giving authentic learning experiences to the participants. The 2020 virtual version of the program effectively engaged in-service teachers with high daily participation and retention rates. Nearly all participants rated the workshops as very good or excellent, and an assessment of participants' learning outcomes was comparable to that of the highly-rated in-person 2018 version of the program. Following the PD session, teachers reported feeling more prepared to facilitate their students' learning, increased inquiry-based science teaching knowledge and skills, and their enthusiasm for utilizing workshop strategies. While there are challenges to implementing virtual learning, virtual teacher PD can be widely adaptable and replicable for many institutions, especially in situations in which distance or finances deter in-person participation.
\end{abstract}

\section{INTRODUCTION}

In March of 2020, we were prepared to conduct an in-person teacher professional development program (TPD) called "GeoTeach," as part of an NIH-funded Science Education Enabling Careers (SEEC) II Program. Past participants of the GeoTeach workshop consistently commented on how much they valued both the hands-on, inquiry-based structure of the activities and the opportunity to connect with other teachers. In response to the COVID-19 spread, however, the possibility of in-person TPD was eliminated by the Centers for Disease Control spring 2020 guidelines, state mandates, and university requirements, and thus, we were forced to adapt the workshop to a virtual setting or cancel the training altogether. If we were to adapt the workshop to a virtual setting, it was important to maintain as much as possible effective TPD practices and core GeoTeach elements.

For many teachers, TPD is not a source of excitement (Ekinci and Acar, 2019), but rather something that occurs during a staff meeting or planning period and often either presents a mandate about new procedures or provides a sales pitch for products for the classroom. This type of professional development has not been shown to be particularly effective or transformative (Fernandes et al., 2018). However, professional development can be an enjoyable and motivating experience, if it is designed and implemented well. While there is no perfect formula for an effective professional development experience, several studies indicate that excellent TPD has the common elements of (1) meeting teacher needs, (2) modeling effective strategies (3) involving teachers in the planning or design of the workshop, (4) engaging active participation and learning, (5) providing long-term engagement, (6) making time for feedback and reflection, (7) offering high-quality instructors and coaching, and (8) focusing on relevant content and student outcomes (Bayar, 2014; Bates and Morgan, 2018; Hubers et al., 2020; Darling-Hammond et al., 2017). Education policy and evaluation researcher Thomas Guskey argues that it can 
be difficult to plan for effective TPD because "varied contexts introduce a web of factors that influence whether or not a particular characteristic or practice will produce the desired results" (Guskey, 2003, p.750). Nonetheless, when professional development is effective, there is a relationship between changes in teacher practices and positive student learning outcomes (Bates and Morgan, 2018; Hubers et al., 2020). This research cumulatively indicates that for a TPD to be successful, it is critical to know participants and tailor sessions to their needs.

All of the University of Alabama at Birmingham's Center for Community Outreach Development (UAB CORD), TPD workshops include these best practices. Although each workshop is tailored to the teachers' content knowledge and skills, workshops have common elements of being learner-centered-first participating in hands-on activities as individual learners, then debriefing in teams to discuss how they would implement the experience in their classrooms. Our TPD participants routinely provided feedback that they enjoyed this aspect and highly valued the opportunities to collaborate with each other. We also conducted long-term development of the workshops over one to three weeks, followed by single-day supplemental workshops during the school year. Graduates of the program have had opportunities to attend another training the following year. Moving this format to an online platform was a unique challenge.

There is strong potential for online teacher professional development to have a meaningful impact. Offering TPD online can expand the impact to reach rural, remote, and international populations (Maher and Prescott, 2017), thus providing virtual TPD to distant participants who may not otherwise be able to attend a multi-day, in-person training, either for personal or financial reasons. Teachers can be given the choice of training platforms based on their interests or self-identified needs. Virtual TPD also allows teachers to complete training on their own schedule (i.e., asynchronously). Online tools can facilitate collaboration and peer learning (Hajisoteriou et al., 2018; Liu, 2012) and generate richer discussions compared to their in-person counterparts (King, 2002). However, in the case of some initiatives like Massive Open Online Courses (MOOCs), problems arise relative to the learner's motivation, participation, and completion (Misra, 2018). Some research suggests that learner performance improves in virtual learning environments as teachers gain more experience and familiarity with the platform (Alves et al., 2017). This suggests that it is worth pushing past any initial problems and pitfalls in virtual TPD. Asynchronous online modules, like most MOOCs, can offer the convenience of adapting to individual schedules. However, a study of over 800 teachers revealed that many participants missed the collaborative nature of face-to-face training and did not like the lack of specificity to them and their classrooms (Collins and Liang, 2015). Some work has demonstrated success in combining asynchronous content delivery with integrated social platforms to facilitate collaboration and community-building among participants (Ostashewski et al., 2011). Significant student performance gains can occur through a strictly online collaborative teacher professional development platform (Compen et al., 2020).

Research on online TPD suggests that TPD has some degree of success and participant satisfaction, but few studies have compared the same program when delivered online vs. in-person. One study focused on migrating a workshop from a face-to-face to an online format found that the two methods provided comparable results without compromising workshop outcomes (Jocius et al., 2021). An analysis of the GeoTeach data collected during and following the virtual and in-person TPD indicates that participants found the virtual (synchronous) workshops as effective and enjoyable as the in-person workshop. Thus, our study adds to the emerging evidence that indicates a high-quality in-person teacher professional development program can be successfully adapted to a high-quality virtual and synchronous approach.

SEEC II Context. The Science Education Enabling Careers (SEEC) II Program's main goal is to develop a method that enhances the transition of students from elementary to middle school science, so that they will be enthusiastic about secondary STEM education, flourish in their education, and pursue biomedical or other STEM careers. The specific aims pertinent to the summer GeoTeach TPD were to: (1) provide training to grade 4-6 teachers and administrators in inquiry-based STEM methods to improve teacher engagement and student STEM learning, and (2) develop formative-focused teacher-student assessment models. This paper describes the successful adaptation of an in-person model to a virtual platform and relevant formative data collected during and after the workshop.

Participants. Teachers were recruited from two large local districts that predominantly include Title I schools that are attended by students from historically underrepresented groups. We shared summer training information with system administrators (with whom we had already established working relationships); having the trust and support of administrators greatly assisted with recruiting. Ultimately, 51 teachers applied for a week of training. An even distribution of 4th, 5th, and 6th-grade teachers applied. We accepted 37 teachers and expected some attrition, but only two participants dropped out. In a typical year, space would have been limited to 12-18 participants, but the virtual platform enabled more people to participate without detracting from the 1:1 facilitation capacity of the workshop. The participants represented a diverse mix of racial backgrounds $(\sim 50 \%$ Black and 50\% white), grade levels taught (fourteen 4th grade teachers, nine 5th grade teachers, and nine 6th grade 
teachers), and school types (participants represented 20 different schools, three school systems, and a mixture of suburban public, urban public, and urban charter schools). Participants were paid a stipend for completing the workshop and also received books and digital resources.

\section{ADAPTING THE SEEC II PROGRAM MODEL}

The SEEC II summer workshop mirrored the model developed from five years of work in SEEC I (i.e., from fall 2014 to spring 2019 with summer workshops offered in 2015-2018). In the SEEC I professional development program for 6th- 8th-grade teachers, participants spent five days training on STEM best practices such as 5E science (Atupan, 2013), the engineering design process, and the eight science and engineering practices. The specific content and pedagogy varied somewhat year to year, depending on participants' needs. Participants spent one day in the field learning about a local resource where students can conduct cross-curricular research and also attended town-hall style presentations with lead researchers to learn first-hand about important topics like climate change. The SEEC I workshops were fully hands-on, with participants experiencing all lessons and pedagogies first as learners and then as practitioners-debriefing and discussing with each other how they would utilize the content and practices in their own classrooms. When individual classroom materials were not provided, module kits were loaned out and participants were given resource-rich binders and books. Participants were paid a stipend for attending and were offered three follow-up days during the subsequent school year. The SEEC I model was effective in increasing teachers' self-efficacy, improving their pedagogical skills and knowledge, and creating an extremely positive atmosphere (Haynie and Albert, 2017). Consistently year to year, teachers reported feeling empowered, supported, and excited following workshop completion.

The in-person cohort of July 2018 was similar to the 2020 virtual cohort. A total of 25 teachers represented 16 different schools and 10 different districts, including Title I urban and suburban schools, faith-based schools, and more affluent suburban schools.

In preparing for the summer $2020 \mathrm{TPD}$, our goal was to adapt the SEEC-I program model to a virtual setting. Critical elements of the program model to be retained in the virtual setting were: (1) opportunities to directly experience lessons hands-on as a learner, (2) chances to debrief and discuss with peer teachers and facilitators, (3) time to connect and collaborate with fellow teachers, and (4) opportunities to learn from experts. Our planning and facilitation team sought to be mindful of the strain of extended screen time. We therefore adapted the six-hour in-person day to three hours of synchronous time (on-camera) in the mornings, followed by asynchronous time in the afternoons (with workshop facil- itators available for support). Facilitators planned lessons that used low-budget or at-home materials. Participants were allowed to select a preference for digital or physical book copies prior to the workshop. Materials were packaged into a kit. Each teacher could then retrieve their kit the week before the workshop from a central, COVID-19-safe location. This inclusion of materials kit enabled retention of many of the qualities of a traditional hands-on workshop. To enable collaboration, Zoom was selected as a platform, and additional tools (Google docs, Jamboards, Mentimeter) were added as Together, these tools were employed to support small breakout groups, chats, shared documents and whiteboards, and formative assessment.

\section{THE VIRTUAL WORKSHOP}

Throughout the five days of the workshop in July 2020, facilitation with collaborative tools kept participants actively engaged. Participants were required to keep their cameras on at all times but were encouraged to dress comfortably, and eat, drink, and use the restroom as needed. We did not find lack of participation or engagement to be an issue (although participants later reported that they would have liked longer breaks). Teachers were pre-assigned to different teams for opportunities to work with a vertical team (i.e., teachers of different grade levels) as well as a horizontal team (i.e., teachers of the same grade level). This gave them time to think about how a skill might build across grade levels, as well as time to dig deep into ideas with peers who teach the same content. Each day, an expert on the day's theme joined the session via Zoom; a number of these experts attended more than one day to get a sense of the workshop's flow or to meet the participants in advance. The ability to casually join the Zoom call enabled the program director (on maternity leave) and project evaluator (located across the country) to participate. Thinking ahead to future training sessions, even when in-person training is advisable, a hybrid model supports the inclusion of presenters from across the country and allows remote and casual participation (e.g., return dropping in for a refresher or potential future participants previewing a session). An unintended benefit was that many participants experienced the Zoom platform, gaining proficiency before the start of the 2020-2021 school year. Few had previously used Zoom in a professional or academic context. Subsequently, in the summer of 2021 we used this model for GeoTeach, bringing participants together in person for three days and meeting virtually with instructors across the country for two days. Former participants were invited to join in the virtual sessions and had the option to pick up hands-on materials in advance.

Workshop Schedule and Design. Our team worked carefully to ensure that all participants would feel that the STEM 
content and pedagogy applied directly to them and their classrooms. We anchored the training in project-based learning (Barron et al., 1998; Afriana, et al., 2016) and growth mindset. Evidence from numerous studies clearly shows that students who learn in a real-world context, where grit and resilience are supported with a growth mindset, can overcome traditional achievement gaps (Dweck, 2016). Our participants embraced both the Project-Based Learning (PBL) and growth mindset philosophies and referred to both throughout the workshop. Participants worked through a hands-on lesson/strategy each of the first four workshop days. On Friday, teachers applied and synthesized their learning by developing a lesson and reflecting on how they would implement it in their classrooms (Table 1).

At the end of each workshop day, participants were asked to reflect on their own teaching methods, knowledge gained from the presenter, and how the new material could be incorporated within their own curriculum. This was shared as a formative assessment using the software Mentimeter.

This space for metacognitive reflection was expanded further on the final day of the workshop (Friday) when the teachers were moved into Zoom breakout sessions based on their grade level. In the concluding session, participants created usable lesson plans, utilizing pedagogical skills learned in the workshop. After collaborating with their fellow colleagues, each grade level group presented their lesson plans to the other participants. Several teachers in the workshop taught multiple grade levels, so it was important for teachers to gain applicable knowledge and lessons for multiple grade levels.

Over the entire course of the week, participants built models and reflected upon their teaching strategies and mindsets. By learning new ways to address science in the classroom, the teachers were able to collaboratively apply their newly learned knowledge by creating STEM-based lessons to incorporate into their curriculum.

Daily Formative Assessment. After each daily session, the participants were asked to report their "glows" and "grows" for the day using the digital tool Mentimeter. Research has shown that even well-meaning TPD does not often solic-

Table 1. Schedule of the Workshop's Activities and Topics for the Week.

\begin{tabular}{cccccc}
\hline Day & Monday & Tuesday & Wednesday & Thursday & Friday \\
\hline Topic & $\begin{array}{c}\text { PBL and } \\
\text { Growth } \\
\text { Mindset }\end{array}$ & $\begin{array}{c}\text { Argument } \\
\text { Driven } \\
\text { Inquiry }\end{array}$ & $\begin{array}{c}\text { Picture } \\
\text { Perfect STEM } \\
\text { 5E Science }\end{array}$ & $\begin{array}{c}\text { STEAM- } \\
\text { Using art } \\
\text { principles to } \\
\text { draw deeper } \\
\text { creativity and } \\
\text { meaning }\end{array}$ & $\begin{array}{c}\text { Synthesis } \\
\text { and } \\
\text { reflection }\end{array}$ \\
Model & $\begin{array}{c}\text { Identify a } \\
\text { Lesson } \\
\text { local health/ } \\
\text { environ- } \\
\text { mental } \\
\text { disparity } \\
\text { and develop } \\
\text { a solution }\end{array}$ & $\begin{array}{c}\text { Earth } \\
\text { and natural } \\
\text { resources }\end{array}$ & $\begin{array}{c}\text { Biomedical } \\
\text { engineering; } \\
\text { developing } \\
\text { prosthetics for } \\
\text { animals }\end{array}$ & $\begin{array}{c}\text { Kinesthetic } \\
\text { physics } \\
\text { and body } \\
\text { mechanics }\end{array}$ & $\begin{array}{c}\text { Development } \\
\text { of a lesson } \\
\text { (with peers) } \\
\text { to use in own } \\
\text { classroom }\end{array}$ \\
& & & & & \\
\hline
\end{tabular}

it participants' beliefs and opinions (Johnson, 2006). It is, however, valuable for workshop facilitators to address these areas and tailor the workshop content to participants (Collins and Liang, 2015). Throughout the week, the teachers consistently reported "grows" of feeling engaged and excited about collaborating with fellow colleagues through hands-on, minds-on interactive strategies and discussions. The "grows" reported by participants included: (1) recognizing the need to maintain a growth mindset; (2) gaining confidence in using digital teaching skills such as Zoom and breakout rooms; and (3) becoming intentional about creating engaging science lessons that fit COVID-19 safety protocols, such as the prevention of sharing lab equipment, 6-feet social distancing requirements, and transitioning hands-on activities from a face-to-face to hybrid or remote learning environment. The level of engagement and excitement was almost palpable throughout the week, and participants' energy remained high each day.

\section{EVALUATION}

We articulated evaluation questions relevant to PD efforts, adapted from Guskey (2000):

1. What are the strengths and challenges in implementing the PD? What might be improved in future efforts?

2. What are the reactions of the participants to the PD? What was valuable? What would they change or improve? What follow-up assistance and resources are needed?

3. What do participants learn as a result of the PD? What content knowledge and skills are gained? In what ways are class plans (including curriculum) impacted?

4. How does PD quality compare to that of previous years (under SEEC-I funding)?

Since SEEC's inception, participants' reactions to the professional development have been an essential evaluative outcome. Assessing participants' reactions to PD is the most common form of evaluation; however, it is important that this information be appropriate, meaningful, and useful. Based on the work of Guskey (2000), our evaluation team determined that the quality of professional development processes (e.g., planning, facilitation, technology use, materials, instruction and modeling, timing) are as important the quality of professional development outputs (e.g., participants' immediate perceptions of the value and impact of the training). Therefore, we sought to develop a post-PD survey that queried both of these areas. Haynie and Albert (2017) developed and validated a 16-item participant PD reaction survey that utilizes a 5 -point Likert scale (1=strongly disagree to $5=$ strongly agree). This survey has been used on the 
SEEC PD outcome surveys since 2017. The internal reliability of the survey for summer 2018 teachers' responses was .84 (Cronbach's Alpha) which is a very good level, indicative of uni-dimensionality. In summer 2020 evaluative data were collected from workshop participants at the end of the week (end of Day 5), including for this measure; the internal reliability level was excellent at 0.89 , even more, indicative of uni-dimensionality compared with the 2018 level.

Increasing teachers' preparation level to help their students is extremely important to the SEEC program. In preparation for the summer 2020 SEEC training, the program evaluator developed a list of student areas and skills for which the training aimed at teachers' preparation. These areas included preparing students to learn science processes and inquiry skills, learn basic science concepts, learn to evaluate arguments based on scientific evidence, etc. This list of preparation areas was vetted with the SEEC PD facilitation team for relevance and completeness and included on the post-PD survey. The success criterion was not a pre-post gain, but simply that $90 \%$ of teachers would feel prepared in most areas $(80 \%)$ following the PD.

Finally, it was important to assess teachers' perceptions of their inquiry-based science teaching knowledge and skills, both before and after the training, to determine the impact of the PD. On the post-PD survey, the following two questions were asked with the following scale options $(1=$ poor, $2=$ fair, $3=$ good, 4=very good, 5=excellent):

- AFTER the PD workshop, I would rate my knowledge or skill in inquiry-based science teaching as:

- BEFORE PD workshop, I would have rated my knowledge or skill in inquiry-based science teaching as:

Data Analysis Methods. Our team analyzed data from measures included on the post-PD survey using Excel to calculate means and frequencies, and SPSS for ANOVA and t-test analyses of pre-post measures. Our analyses of qualitative data used Microsoft Word and Excel. Qualitative coding schemes were used to analyze and synthesize open-response items on teacher feedback surveys.

\section{RESULTS}

Evaluation Question 1. What are the strengths and challenges in implementing the PD? What might be improved in future efforts? This will be addressed in the discussion and lessons learned.

Evaluation Question 2. What are the reactions of the participants to the PD? What was valuable? What would they change or improve? What follow-up assistance and resources are needed?

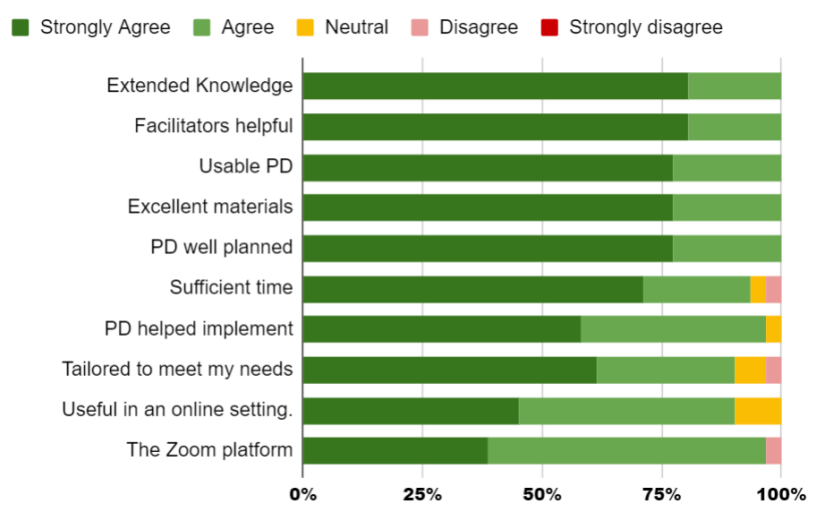

Figure 1. Post-TPD, over $90 \%$ of participants agreed or strongly agreed with positive statements about the workshop's effectiveness and usefulness.

PD was Rated as Very High Quality. Following the summer 2020 PD week, 32 teachers responded to 10 items about the quality of the PD (Figure 1). The scale exhibited very good reliability, Cronbach's alpha $=0.89$. The results show strong levels of agreement with all positive ratings about the PD, ranging from 4.32 to 4.81 (Strongly Disagree $=1$ to Strongly Agree $=5$ ). Relatively lower average ratings (but still very high agreement) were found for items related to virtual learning settings. Overall, $97 \%$ of participants rated the workshop quality as very good or excellent.

Most PD Days were Highly Valued. Figure 2 indicates that most summer 2020 PD days were highly valuable to all or nearly all of the teachers. Thursday's STEAM (Science, Technology, Engineering, Art, and Math) lesson was valuable to about $69 \%$ of the participants. The teaching artist who presented the STEAM lesson found the shift to a digital platform to be more difficult than expected. Our research did not probe participants about attitudes towards utilizing STEAM in general, although in past work we have found secondary teachers to be more hesitant than elementary teachers about the incorporation of art into STEM.

Teachers Appreciated Many Aspects of the PD. The teacher participants reported via post-workshop survey their most

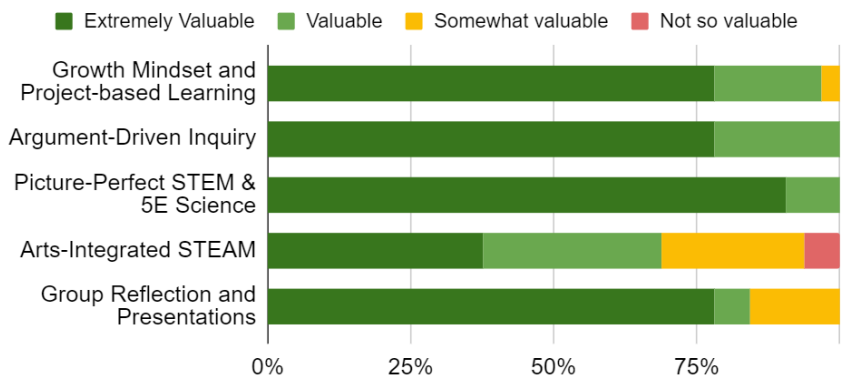

Figure 2. The majority of participants rated most topics as "extremely valuable" with the exception of learning about art integration into STEM, which was rated at least "valuable" by about $70 \%$ of participants. 
valued workshop aspects were: (1) collaborating with other teachers (e.g., via the breakout rooms), (2) the engaging/ hands-on nature of the workshop, (3) Argument-Driven Inquiry, Picture Perfect, and 5E stem, (4) receiving lesson planning resources.

One teacher shared, "I like how each minute of the workshop was valuable. No one read a PowerPoint to us. We always had something tangible to turn in after each break-out session. Each group member had access to the google docs and interactive maps." The only improvement to the workshop that participants named was longer breaks.

Teachers Planned to Use Many Tools from the Workshop. Both during the workshop and reflecting on the post-PD survey, participants enthusiastically mentioned their plans to use many of the PD tools and resources in their classrooms, including: (1) Argument-Driven Inquiry (Sampson et al., 2018), and (2) Picture Perfect, STEM 5E learning, Engagement strategies (Morgan and Ansberry, 2017).

Evaluation Question 3. What do participants learn as a result of the PD? What content knowledge and skills are gained? In what ways are class plans (including curriculum) impacted?

After PD, Teachers Felt Prepared to Help Their Students. Data indicated that nearly all of the teachers felt that the PD prepared them to help their students in almost every way. In particular, $100 \%$ of teachers reported they were prepared or very prepared to (1) increase students' interest in science and (2) prepare them for further study in science. And $90 \%$ or above of participants felt prepared for very prepared to help students (3) learn important terms and facts in science, (4) learn science process and inquiry skills, (5) how to communicate ideas in science effectively, and (6) learn to evaluate arguments based on evidence. Preparing for standardized testing was the one area of preparation with lower ratings, although this type of preparation is debatably not within the scope of the SEEC goals.

Teaching Knowledge and Skills Increased. Figure 3 indicates that teachers' retrospective ratings of their skills before PD (average of $3.0=$ good) increased significantly (chisquare, $\mathrm{p}<.0001$ ) to very good (average of 4.2 ) after the PD experience. Most teachers (80\%) rated themselves at least one point higher after the PD, and no teachers rated themselves as poor or fair after the PD.

Evaluation Question 4. How does PD quality compare to that of previous years (under SEEC-I funding)?

PD Quality Ratings Were Comparable to 2018. PD quality ratings were compared to those of 2018 summer PD; both

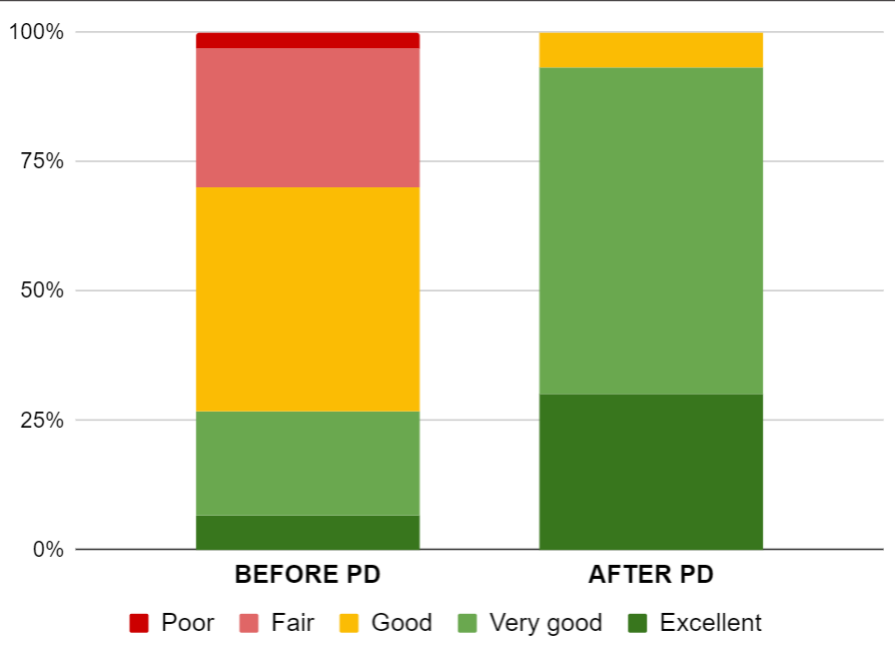

Figure 3. Teacher self-ratings of inquiry-based science teaching knowledge and skills dramatically improved post-PD (26.7\% percent self-reported being "very good" or "excellent" pre-PD, with $93.3 \%$ percent self-reporting as being "very good" or "excellent" post-PD).

workshop evaluations were conducted by the same external review team using the same questions and measurement scale. Figure 4 indicates that for common items, the high levels of positive statements in 2018 (average of 4.7 out of 5.0 points) were retained in the summer 2020 virtual training (average 4.7 of 5.0 points). Comparing the two years by item, the greatest gain in $2020(+.27$ points) was for the statement "this PD will extend my knowledge skills, and performance." The greatest decrease in 2020 ( -.21 points) was for the statement "the facilitators helped me understand how to implement my learning." Given that the training in 2020 was held virtually due to COVID-19 concerns, this small loss is likely related to the inability of the instructor to walk around and interact 1:1 with participants in a physical space as they worked through lessons as learners.

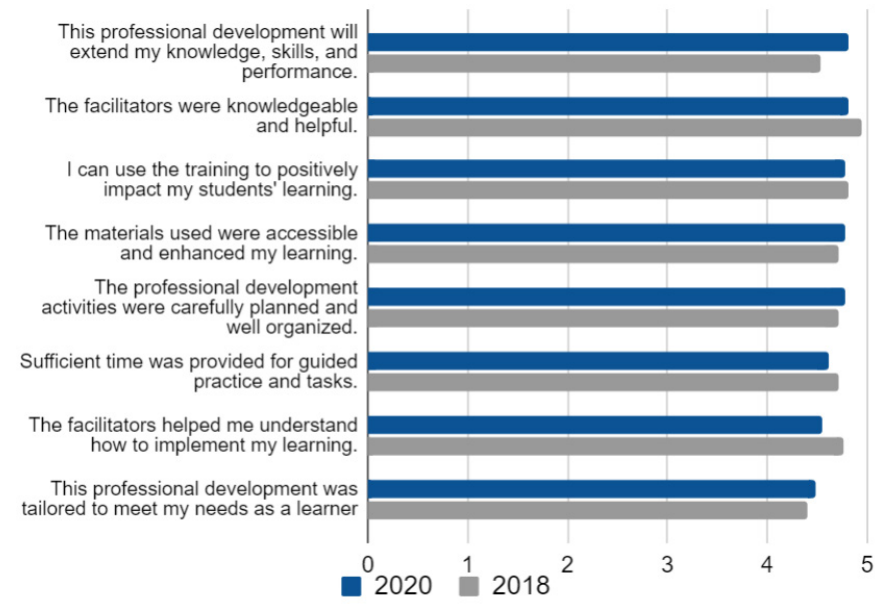

Figure 4. SEEC TPD quality in virtual summer 2020 was comparable to ratings from in-person summer 2018 (1=Strongly Disagree, 5=Strongly Agree). 


\section{TEACHER REFLECTIVE COMMENTS}

Many participants took time to send comments of appreciation for the workshop and workshop facilitators either at the end of a session or separately via email. One teacher shared:

I am ready to implement these in my classroom! I am ready to use ADI in my energy unit! I am also ready to use the 5 E model and use the Picture Perfect book in my reading block. We will have a makerspace at our school and I am excited to work with that teacher with the engineering aspects of these lessons.

Several teacher reflective statements are listed below as representative of the overall feeling of the participants throughout the week.

"Loved this! It gave me more of a growth mindset." (After day 1)

"Thank you! I love this workshop. I had to show my husband the shark. He is a veterinarian so he had to add his ideas too! I love it!" (After day 3, discussion of the creation of prosthetic limb)

"This is the best PD I've had since the pandemic has started! Everyone's doing an AMAZING job." (After day 3)

"Thank you for such an amazing PD opportunity!! Seriously!! I've learned so much this week and can't wait to implement it all this school year!!" (After day 5)

"Thank you so much for the workshop! I am looking forward to digging deeper into the resources you gave us. Thank you again!"' (After day 5)

\section{DISCUSSION}

The five-day PD program fitted very well into the virtual setting in summer 2020. Nearly all of the 35 participants rated the PD as very good or excellent. Quality ratings were comparable to the high-quality PD accomplished in 2018, although summer 2020 was virtual and the hands-on activities were carried out in physical isolation. This was very gratifying to the staff and teachers, given the challenges of the pandemic and the novelty of virtual-only training. This was largely due to the very active facilitation team and the engagement of the participating teachers, and the ability to engage teacher participants virtually while navigating the teaching/learning of content and the use of online tools. Other research into COVID-19 virtual learning has noted a potential loss of academic integrity (Mukhtar et al., 2020). Our summer participants did not receive as many instructional hours as previous participants in face-to-face workshops, but they still valued the PD and gained in preparation to teach hands-on science in the coming year. Our evaluation did not specifically examine the level of academic integrity, but other data (e.g., the value of workshop content and materials) suggest that the academic integrity of the original program was maintained through the transition to a virtual platform.

The four critical elements of TPD (from 2015-2018) were still possible in the virtual setting. These elements are (1) opportunities to directly experience lessons hands-on as a learner, (2) chances to debrief and discuss with peer teachers and facilitators, (3) time to connect and collaborate with fellow teachers, and (4) opportunities to learn from experts. These are consistent with elements generally found to be important to online learning (Nambiar, 2020; Philipsen et al., 2019; Lockee, 2021). For anyone adapting to a virtual model, we suggest making the program hands-on by either mailing materials or making materials easily available for advanced pickup. The chat feature of Zoom and breakout rooms enabled debriefing, discussion, and collaboration time, including "after class" time for anyone interested in staying around longer. Finally, although our experts were local, they were able to conveniently attend the workshop and lead their respective sessions (in the 2021 TPD, we included non-local experts).

Following the TPD, teachers reported: feeling prepared to help their students, gains in their inquiry-based science teaching knowledge and skills, and consistent enthusiasm for utilizing Argument-Driven Inquiry, Picture Perfect engagement strategies, and STEM 5E learning in their classrooms. These data suggest that it is possible to implement virtual professional development without losing key elements that make TPD effective and enjoyable experiences for participants. The use of virtual training would allow for more participant involvement and can make a multi-day training financially or logistically feasible for teachers who may be limited by financial, time, or geographical barriers.

While we still believe in the importance of time spent face-to-face for collaboration and relationship-building, we also recognize that the ability to host an online workshop opens doors and removes obstacles to equitable access. Virtua; TPD can build community in ways that face to face does not give rise to (Lohman, 2020). It is clear that elements of learning in a virtual setting exist that can enhance a learner's experience and connect them with people and experiences that would not be possible in a face-to-face workshop.

Lessons Learned. What was it that worked so well with this virtual PD that could be transferred to other settings and contexts? We believe it was a combination of essential factors that include:

1. Strong and appropriate PD content for teachers of grade 
4-6 science (hands-on and inquiry-based materials, aligned to content standards)

2. Facilitators' skills in engaging participants included strong content knowledge, pedagogical content knowledge, and facilitation skills

3. Facilitators' skills with online tools (Zoom, Google tools, etc.)

4. Facilitators' willingness to listen to participants' daily feedback and make adjustments as needed, improving both workshop quality and participants' sense of being valued

5. A strong facilitation team committed to the participants and the success of the team more than individual gain

In what ways is this scalable? The provision of facilitator training in all of these key areas is essential to the success of virtual (or hybrid) TPD. These skill-sets vary greatly and are not likely gained in one "place" but acquired over time. One suggestion is to have skill development plans for TPD facilitators, coupled with whole team meetings to discuss the design and development of upcoming TPD programs. Studying and applying best practices, such as listed here, can support these efforts.

Many leaders in the education community have challenged the idea of "returning to normal" and instead ask that, as a community, we think about how to come away from the COVID-19 better than before. Research and published stories are beginning to show ways in which that is possible (Sahlberg, 2021). Similarly, we in STEM education are tasked as a community to think about how to incorporate technology in a way that enhances instruction, rather than simply replacing physical items with digital ones. Emerging research shows that in some settings students reported feeling that the use of technology in a course/virtual setting improved their understanding of course materials (Al-Labadi and Sant, 2021). One positive impact of the COVID-19 pandemic on K-12 education is the dramatic increase in students who have personal devices for use in the classroom and at home, as well as an increase in collaborative digital tools and teacher familiarity with these resources. Moving forward, it will be important to be sensitive to the digital fatigue that many people feel, but also to consider what new doors have been opened for including technology and using it to enhance a learner's experience.

Limitations. A limitation of this evaluation is that it did not follow up with teachers during the school year to measure to what degree workshop strategies were implemented; however, longer term teacher outcome measures of pedagogical approach and science content knowledge are currently being collected from teachers trained in summer 2020. Given the unique challenges of teaching in the year of COVID-19, such comparisons were difficult; however, future examination of the long-term outcomes of these teachers and others would be valuable to compare virtual compared to in-person TPD, to test if either platform translates to significant losses or gains in-classroom implementation following the professional development. Hodges et al. (2020) suggest caution when comparing instruction that was planned for an online setting to emergency remote teaching (ERT) and suggest that "evaluation of ERT should be more focused on the context, input, and process elements than product (learning)," (Hodges et al., 2020, p. 11). As our emergency changes were not intended to be carried out long-term as the format of the program, we did not evaluate using different criteria or considerations from our typical in-person evaluation. This perhaps creates some limit on how items can be compared, and it would strengthen findings of the virtual workshop if we could compare them to a simultaneous in-person workshop. A major difference in the two formats was the number of daily instructional hours. An excellent future area of exploration would be the comparison of the number of in-person versus virtual instructional hours needed to achieve the same learner outcome.

\section{CONCLUSIONS}

Emerging research, like this study, suggests that traditional, in-person teacher professional development can be adapted to a synchronous, virtual setting effectively. We suggest that, when possible, such adaptations include some physical elements like a materials kit or activities that utilize common household items. It is also important to keep participants engaged using tools for feedback and collaboration and be mindful of the strain of extended screen time. Although there is a great value in meeting face to face, the benefits of a virtual setting including removing barriers of distance could allow more people and more diverse groups of collaborators to benefit from participating in a TPD.

\section{AUTHOR INFORMATION Corresponding Author}

J. Michael Wyss, Department of Cell, Developmental and Integrative Biology, The University of Alabama at Birmingham. 933 19th Street, South, Birmingham, AL 35294. jmwyss@uab.edu

\section{Author Contributions}

All authors contributed equally to this manuscript. 


\section{ACKNOWLEDGMENTS}

The authors would like to thank the wonderful team of teachers who brought so much heart and insight to each session of the workshop, as well as, each of the expert guest presenters for their work in adapting to a virtual setting.

\section{FUNDING SOURCES}

This study was funded in part by SEPA awards from the National Institutes of General Medicine grants GM132967 and GM111369. The authors declare they have no financial conflicts of interest related to this study.

\section{ABBREVIATIONS}

CORD: Center for Community Outreach Development; ERT: Emergency Remote Teaching; MOOCs: Massive Open Online Courses; PBL: Project-Based Learning; PD: Professional Development; SEEC: Science Education Enabling Careers; TPD: Teacher Professional Development; UAB: University of Alabama at Birmingham

\section{REFERENCES}

Afriana, J., Permanasari, A., and Fitriani, A. (2016). Project based learning integrated to STEM to enhance elementary school's students scientific literacy. Journal Pendidikan IPA Indonesia, 5(2), 261-267.

Al-Labadi, L., and Sant, S. (2021). Enhanced learning experience using technology in class. JOTSE: Journal of Technology and Science Education, 11(1), 44-52.

Alves, P., Miranda, L., and Morais, C. (2017). The influence of virtual learning environments in students' performance. Universal Journal of Educational Research, 5(3), 517-527.

Atupan, J.M. (2013). 5E's instructional model. Best Practice in Science Teaching

Barron, B. J., Schwartz, D. L., Vye, N. J., Moore, A., Petrosino, A., Zech, L., and Bransford, J. D. (1998). Doing with understanding: Lessons from research on problem-and project-based learning. Journal of the Learning Sciences, 7(34), 271-311.

Bates, C. C., and Morgan, D. N. (2018). Seven elements of effective professional development. The Reading Teacher, 71(5), 623-626.

Bayar, A. (2014). The components of effective professional development activities in terms of teachers' perspective. Online Submission, 6(2), 319-327.

Collins, L. J., and Liang, X. (2015). Examining high quality online teacher professional development: Teachers' voices. International Journal of Teacher Leadership, 6(1), 18-34.
Compen, B., De Witte, K., and Schelfhout, W. (2021). The impact of teacher engagement in an interactive webinar series on the effectiveness of financial literacy education. British Journal of Educational Technology, 52(1), 411-425.

Darling-Hammond, L., Hyler, M. E., and Gardner, M. (2017). Effective teacher professional development. Learning Policy Institute.

Dweck, C. (2016). Mindset: The New Psychology of Success: Penguin Random House.

Ekinci, E., and Acar, F. E. (2019). Primary school teachers' opinions on professional development (professional development model proposal). Journal of Education and Training Studies, 7(4), 111-122.

Fernandes, G. W. R., Rodrigues, A. M., and Ferreira, C. A. (2020). Professional development and use of digital technologies by science teachers: A review of theoretical frameworks. Research in Science Education, 50(2), 673-708.

Guskey, T. (2000). Evaluating Professional Development. Thousand Oaks, CA: Corwin Press.

Guskey, T. R. (2003). What makes professional development effective? Phi Delta Kappan, 84(10), 748-750.

Hajisoteriou, C., Karousiou, C., and Angelides, P. (2018). INTERACT: Building a virtual community of practice to enhance teachers' intercultural professional development. Educational Media International, 55(1), 15-33.

Haynie, K., and Albert, J. (2017). Science Education Enabling Career (SEEC): July 2017 Professional Development Evaluation Report. A report submitted to the CORD center at The University of Alabama, Birmingham. Haynie Research and Evaluation: Skillman, NJ.

Hodges, C., Moore, S., Lockee, B., Trust, T., and Bond, A. (2020). The difference between emergency remote teaching and online learning. Educause Review, 27(1), 1-9.

Hubers, M. D., D. Endedijk, M., and Van Veen, K. (2020). Effective characteristics of professional development programs for science and technology education. Professional Development in Education, 1-20.

Jocius, R., Joshi, D., Albert, J., Barnes, T., Robinson, R., Cateté, V., Dong, Y., Blanton, M., O’Byrne, I., and Andrews, A. (2021, March). The Virtual Pivot: Transitioning Computational Thinking PD for Middle and High School Content Area Teachers. In Proceedings of the 52nd ACM Technical Symposium on Computer Science Education (pp. 11981204).

Johnson, C. C. (2006). Effective professional development and change in practice: Barriers science teachers encounter and implications for reform. School Science and Mathematics, 106(3), 150-161.

King, K. P. (2002). Identifying success in online teacher education and professional development. The Internet and Higher Education, 5(3), 231-246. 
Liu, K. Y. (2012). A design framework for online teacher professional development communities. Asia Pacific Education Review, 13(4), 701-711.

Lockee, B. B. (2021). Shifting digital, shifting context:(re) considering teacher professional development for online and blended learning in the COVID-19 era. Educational Technology Research and Development, 69(1), 17-20.

Lohman, L. (2020). Leveraging sociomaterial practices to build elearning literacy in "suddenly online" professional development. Journal of Literacy and Technology, 21(3), 59-81.

Maher, D., and Prescott, A. (2017). Professional development for rural and remote teachers using video conferencing. Asia-Pacific Journal of Teacher Education, 45(5), 520-538.

Misra, P. (2018). MOOCs for teacher professional development: Reflections and suggested actions. Open Praxis, 10(1), 6777.

Morgan, E. R., and Ansberry, K. R. (2017). Picture-perfect STEM lessons, 3-5: Using children's books to inspire STEM learning.

Mukhtar, K., Javed, K., Arooj, M., and Sethi, A. (2020). Advantages, Limitations and Recommendations for online learning during COVID-19 pandemic era. Pakistan journal of Medical Sciences, 36(COVID19-S4), S27.

Nambiar, D. (2020). The impact of online learning during COVID-19: Students' and teachers' perspective. The International Journal of Indian Psychology, 8(2), 783-793.

Ostashewski, N. M., Reid, D., and Moisey, S. (2011). Applying constructionist principles to online teacher professional development. The International Review of Research in Open and Distributed Learning, 12(6), 143-156.

Philipsen, B., Tondeur, J., Roblin, N. P., Vanslambrouck, S., and Zhu, C. (2019). Improving teacher professional development for online and blended learning: A systematic meta-aggregative review. Educational Technology Research and Development, 67(5), 1145-1174.

Sampson, V., Murphy, A., Lipscomb, K., and Hutner, T. (2018). Argument-driven inquiry in earth and space science: Lab investigations for grades 6-10. National Science Teachers Association.

Sahlberg, P. (2021). Does the pandemic help us make education more equitable? Educational Research for Policy and Practice, 20(1), 11-18. 